Artigo Original

\title{
Freud antes de Freud em São Paulo
}

\section{Freud before Freud in São Paulo}

\author{
Afonso Carlos Neves ${ }^{1}$
}

\section{RESUMO}

Introdução: O livro de Franco da Rocha, "O pansexualismo na doutrina de Freud", de 1920, tem sido considerado como o marco inicial da divulgação das idéias de Freud em São Paulo; a aceitação da teoria freudiana pelos artistas ligados à Semana de Arte Moderna de 1922 deu um caráter próprio ao desenvolvimento dessas idéias em São Paulo. Método: Levantamento de citações sobre Freud em publicações médicas paulistas antes de e até 1920 inclusive. Resultados: Pudemos constatar a citação de Freud e suas idéias a partir de 1908, com onze citações até 1920. Discussão: Esse achado permite adicionar, à noção anterior, uma participação do ambiente científico médico paulista, na discussão das idéias de Freud, bem antes dessa data e permite ter-se uma idéia mais dinâmica desse contexto no início do século XX em São Paulo, diferentemente do que tem sido suposto até o momento.

Unitermos: História da Medicina, Psicanálise, Teoria Freudiana, Publicações, Metodologia.

Citação: Neves AC. Freud antes de Freud em São Paulo. Rev Neurocienc 2006; 14(3):127-134.

\section{SUMMARY}

Introduction: The book by Franco da Rocha, "The pansexualism in Freud's doctrine", from 1920, has been considered the initial mark in the spreading of Freud's ideas in São Paulo; the acceptance of the Freudian theory by the artists linked to the Week of Modern Art in 1922 gave a special character to the development of these ideas in São Paulo. Methods: It was looked for citations of Freud in the medical magazines of São Paulo, before and including 1920. Results. We observed the citation of Freud and his ideas since 1908, with eleven citations until 1920. Discussion: This findings may add, to the former notion, that the medical and scientific environment have participated in the discussion of Freud's ideas several years before that date and it can gave a more dynamic vision of that context in the beginning of the XX century in São Paulo, diversely of which was supposed until this moment.

Keywords: History of Medicine, Psychoanalysis, Freudian Theory, Publications, Methodology.

Citation: Neves AC. Freud before Freud in São Paulo. Rev Neurocienc 2006; 14(3):127-134.

\section{INTRODUÇÃO}

Tornou-se convencional, ou mesmo tradicional, a citação de que a primeira menção a Freud, em São Paulo, teria ocorrido em 1919, em uma publicação de Franco da Rocha no jornal "O Estado de São Paulo" intitulada "Do delírio em geral", sendo reforçado esse marco pelo fato de, em 1920, Franco da Rocha ter publicado o primeiro livro no Brasil sobre Freud, intitulado "O pansexualismo na doutrina de Freud", conforme podemos observar na publicação de 2006, da socióloga e psicanalista Carmen LMV Oliveira, intitulada "História da Psicanálise - São
Paulo (1920-1969)", publicação essa referente à tese de doutorado da mesma autora, defendida em Paris e orientada por Elisabeth Roudinesco ${ }^{1}$, o que certamente valoriza esse dado. Além disso, eventualmente encontrase também a citação de que, antes dessa obra, Franco da Rocha já falava de Freud em suas aulas².

A repetição, na literatura, desses fatos como tendo sido pioneiros em São Paulo, pode ter feito com que não se desse atenção à possibilidade de ter havido alguma outra citação a Freud, anteriormente a essa, nas publicações médicas paulistas. Outra possível

Trabalho realizado na Disciplina de Neurologia da UNIFESP

1 - Médico Neurologista da Disciplina de Neurologia da UNIFESP, Coordenador do Necon - Núcleo de Estudos do Conhecimento, grupo interdisciplinar da Disciplina de Neurologia e do CeHFi - Centro de História e Filosofia das Ciências da Saúde da Unifesp.

Endereço para correspondência: Rua Albano Eugenio Dahmer, 33 - Cotia, S.P. Brasil - CEP:06710-750. E-mail: acarlosneves@uol.com.br

Trabalho recebido em 10/07/06. Aprovado em 10/08/06 
explicação é de que pode não ter havido interesse, por parte dos estudiosos de Freud e da psicanálise, em fazer levantamentos em publicações médicas paulistas anteriores a esse período, talvez até pelo próprio valor dado ao primeiro livro brasileiro totalmente dedicado às idéias de Freud.

Esse primeiro livro sobre Freud ganhou um pouco da marca de um "mito fundador" da presença da doutrina freudiana em nosso meio, paulista ou mesmo nacional, embora haja a noção de que Freud teria "chegado" nos anos 1910 entre os médicos do Rio de Janeiro e nos anos 1920 em São Paulo; sendo, neste segundo caso, mais associado ao Movimento Modernista ligado à Semana de Arte Moderna de 1922, já que os artistas ligados a esse movimento foram francamente adeptos do pensamento freudiano'.

Assim como em outras áreas, em estudos sobre história da Psiquiatria têm sido estudados os chamados "mitos de origem" ou "mitos de fundação" de seu início e de seu desenvolvimento, sendo enfocado, por exemplo, o papel de Pinel no contexto da Psiquiatria e da Clínica. Conforme P Vandermeersch, a função dos mitos de origem é legitimar "o presente" no tempo em que ele se estabelece como tal; esse autor estabelece dois pontos de questionamento em relação aos tais que são: as "belas histórias" sempre narradas internamente nas diferentes disciplinas e se esses mitos chegaram a estabelecer o que pretendiam ${ }^{3}$.

Como esse fenômeno dos mitos de origem ocorre em diversas situações, é plausível que entre nós também possam ter havido situações similares. Nesse sentido, por outro lado, a palavra mito não necessariamente se refere a um acontecimento fictício ou que não tenha existido, mas pode estar ligado a um determinado caráter que um fato passou a assumir, a partir de determinado contexto ${ }^{4}$.

Talvez o lançamento da obra de Franco da Rocha não tenha chegado a ter a mesma aura que cercou outros eventos nesse contexto de mitos de origem, mas situada em determinada época e situação obteve sua notoriedade.

O lançamento do livro em 1920 pode ter delimitado o início de um novo paradigma no entendimento da mente e suas doenças no Brasil. Nesse sentido, usando a conceituação de Thomas Kuhn - que estabeleceu o estudo das transformações científicas através da sucessão de paradigmas -, no período intermediário entre diferentes paradigmas que se sucedem, há uma dificuldade cada vez maior do paradigma anterior em encontrar soluções para os problemas emergentes, enquanto que indícios de novas soluções passam a surgir no campo científico em questão, em geral levantando questões polêmicas ${ }^{5}$. Sob essa visão, podemos supor que o paradigma freudiano talvez possa ter iniciado sua presença em
São Paulo antes de ter sido formalmente aceito no meio científico e artístico.

Este artigo não visa desvalorizar o marco do primeiro livro sobre Freud no Brasil, publicado por Franco da Rocha, nem aqueles que reforçam esse fato como importante. O objetivo deste trabalho é verificar a existência de citações precedentes no meio paulista, que já possam ser indícios de uma penetração da doutrina freudiana em São Paulo. Embora não seja o cerne deste artigo, decorre desses fatores um eventual questionamento de metodologias de levantamentos de dados e recortes de investigação.

\section{MATERIAL E MÉTODO}

Foram procuradas citações do nome de Freud, nos periódicos médicos publicados em São Paulo até 1920 inclusive, existentes na Biblioteca do Centro de História e Ciências da Saúde da UNIFESP.

O critério para a escolha das publicações foi: publicações médicas editadas em São Paulo no período de tempo até 1920 inclusive. Foi feito um rastreamento em todas as publicações; portanto, não foram selecionados fascículos por quaisquer critérios do tipo sorteio.

Não foi um critério, e nem objetivo, detectar o "número total" de citações de Freud em São Paulo, haja vista que o fato de haver alguma citação já implica em dado inédito.

As citações obtidas foram consideradas suficientes para atingir o objetivo de encontrar citações de Freud em São Paulo, que antecederam ou ocorreram no ano de 1920.

\section{RESULTADOS}

Foram encontradas citações na "Gazeta Clinica", nos "Annaes Paulistas de Medicina e Cirurgia", bem como nos "Annaes do Primeiro Congresso Medico Paulista", que serão referidas na ordem cronológica de publicação. As citações procuram seguir a ortografia original.

\section{1 - 1909 - Gazeta Clínica}

\section{- Ano VII - Abril - n.4, páginas 44-46. Título do artigo: "Ideas Fixas e Obsessões"6 \\ Autor: Dr. Jayme Gonçalves}

O Dr. Gonçalves inicia seu artigo relatando os diversos tipos de fobia que podem acometer os neurastênicos: metalofobia, hidrofobia, antrofobia, zoofobia, tisiofobia, tanatofobia, necrofobia, fobofobia. A seguir refere diversos tipos de manias classificadas entre as obsessões como: dipsomania, cocainomania, morfinomania, cloralmania, 
antipirinomania e outras que ele associa ao progresso da farmácia química. Desse modo, cita situações em que há dor de estômago ou de cabeça e que, receitado o medicamento, o paciente passa a andar com o mesmo por toda parte e faz o possível para obtê-lo e estocá-lo. Refere que "todos os pacientes reconhecem o mal que praticam, mas o desejo é mais forte do que a vontade". No item de impulsos obsessivos ele inclui a piromania e a cleptomania.

Na medida em que o autor vai discorrendo sobre esses temas, vai citando diversos autores. Em um determinado parágrafo, à página 45, ele cita:

"Breuer, Freud e Janet descreveram as idéas fixas subconscientes. Estas idéas que podem ter consequencias graves só se manifestam durante os ataques hystericos, os sonhos, os accessos somnambulicos. Ellas ficam fora da consciencia, no estado normal."

No exemplar que consultamos da Gazeta a letra "u" de Breuer e Freud saiu como "n"; nessas publicações os erros de letras em nomes estrangeiros eram relativamente comuns. Ao mesmo tempo em que são casuais, esses erros podem indicar ainda uma falta de familiaridade com esses nomes no trabalho de impressão.

\section{2 - 1910 - Gazeta Clínica}

- ano VIII - julho - páginas 73-75.

Título do artigo: "A Physio-pathologia da vontade"”

\section{Autor: Dr. A Villas Boas}

O autor se refere ao estudo científico das funções cerebrais, livres dos conceitos metafísicos. Ele cita diversos autores de peso na época e suas diferentes explicações para os fenômenos psíquicos. Na página 74, ele escreve o seguinte parágrafo:

"Freud compreende as obsessões e phobias como uma nevrose anciosa de origem sexual, e devida a tensão genetica provocada pela abstinencia ou por excitações genesicas frustras".

\section{3 - 1914 - Annaes Paulistas de Medicina e Cirurgia}

Março - Anno II - vol. II - no 3 - páginas 65-75.

Título do artigo: "Paranoia e Syndrome Paranoide""

\section{Autor: Franco da Rocha.}

Neste artigo o autor discorre a respeito das diversas teorias sobre a paranóia, citando diversos pesquisadores, e usando até mesmo um trecho de Shakespeare em inglês para ilustrar sua exposição. Após expor o caso de uma paciente acometida do quadro em discussão, à página 71 ele escreve o seguinte:
"Essa observação ilustra muito bem a descrição geral da paranóia. Aqui o principal conteúdo das idéias delusorias nace evidentemente do instinto sexual: é o amor. Vem agora a pêlo algumas considerações sobre a doutrina de Freud."

"De pleno acordo com o Prof. Bleuler, pensamos que Freud, quando tenha exageros inaceitaveis na sua psychologia, tem o mérito de ter posto em relevo a influencia do impulso sexual na origem das psychoses, coisa que se costumava de certo modo desprezar."

Na página 72 há este outro parágrafo:

"Os críticos das idéias de Freud acusam os dicipulos deste do abuso na interpretação dos symbolos, para referirem este ou aquele fato á ação do instinto sexual agindo das profundezas do inconsciente sobre a personalidade consciente."

Ainda na página 72, no rodapé, o autor faz a seguinte citação:

"Paul Ladame julga que a doutrina de Freud é uma ilusão e, sob o ponto de vista terapeutico, levaria ao absurdo de aconselhar meios que seriam subversivos da moral sexual. Affirma ainda o psychiatra de Genebra que a castidade não é prejudicial, mas sob a condição de se evitarem os momentos de excitação especial. Essa é muito boa! Evitar como? Si nem no Paraíso o foi possível... Ladame teria posto a questão nos verdadeiros termos si dissesse: a castidade póde evidentemente não ser prejudicial; isso, porém, depende do temperamento individual."

Franco da Rocha faz uma série de reflexões sobre a paciente em questão, usando de argumentações próprias à doutrina freudiana em relação à libido e à sexualidade, comparando a situação entre homens e mulheres na sociedade e concluindo seu artigo com a pergunta: "Porquê essa desigualdade? Será porque as leis são feitas pelos homens?"

\section{4 - 1914 - Gazeta Clínica}

- ano XII - fevereiro - páginas 45-46.

- artigo reproduzido do "Correio Paulistano" de um original de Paris em dezembro de 1913.

Título do artigo: "Os milagres de Esculapio" 9

\section{Autor: Dr. G Dumas}

O autor de refere a recentes escavações e restaurações de antigos templos gregos, entre eles o de Esculapio. A partir daí ele descreve como ocorriam as atividades dos doentes que procuravam esse local. Ressalva ele que, havendo distância de dois mil anos, as curas referidas devem ser consideradas como podendo ter diversas explicações. Como o sonho era um 
importante componente no processo de cura de então, à página 46 ele cita Freud:

"Si como hoje pensam varios psychologos da escola de Freud e o proprio Freud, a maioria dos sonhos são consequencias dos nossos desejos ou dos nossos receios, os peregrinos que iam consultar Esculapio estavam admiravelmente preparados para os sonhos divinos, pela sua fé, pela sua expectativa, por todas as esperanças que depositavam na apparição do deus".

5 - 1914 - Gazeta Clínica - setembro - página 194.

Da seção "Das Revistas”, do Journal de Psychologie, no 1, 1914

Título do artigo: "As theorias psychologicas e metapsychologicas da demência precoce"10

Autor: A Hesnard.

Neste artigo, que na Gazeta Clínica é um resumo do artigo de uma revista francesa, pode-se ler a citação da "psycho-analyse" e sua utilização, bem como o nome de Jung.

Este é o texto correspondente à resenha do artigo da revista francesa, conforme consta na Gazeta:

"A. Hesnard expõe a theoria psychologica ou melhor methapsychiatrica da demencia precoce, que nasceu em Zurich sob a influencia das idéias do dr. Freude (de Vienna) difundindo-se rapidamente nos paises de língua allemã. Os adeptos dessa doutrina applicam systematicamente aos alienados, especialmente áquelles a que põem a etiqueta de dementes precoces, o methodo de psycho-analyse de Freude, que, no sentido mais lato, comporta todas as technicas do interrogatorio, do inquerito da observação do paciente, e da historia psychica dos symptomas".

"Os doentes que serviram de edificação das theorias da escola de Zurich são ainda pouco numerosos, mas cada psycho-analyse demanda mezes, ás vezes annos... Se se considera que, dada a larguissima, compreensão da sua noção de demencia precoce, essa doença constitue para os psycho-analystas a mais frequente de todas $(70,80$ p. 100 dos doentes de Jung no asylo de Burghölzli) concebe-se que no seu espirito a psycho-analyse revista uma importancia capital. 'Se se considera, enfim, que a psycho-analyse é um methodo de psychotherapia ao mesmo tempo que de estudo das doenças mentaes, e que os seus partidarios affirmam ter melhorado senão curado dementes precoces projectando a luz do inquerito psychologico nas profundezas até então impenetraveis da sua mentalidade, comprehende-se que os medicos de Zurich não hesitem em proclamar que vão operar uma revolução na medicina mental, con- duzindo-nos, segundo Jung, a uma orientação nova da psychiatria'".

\section{6 - 1916 - Anais do Primeiro Congresso Médico Paulista}

- páginas 176 - 185.

Título do artigo: "Debilidade nervosa - reações elementares do Sistema Nervoso" 11

\section{Autor: Dr. A Austregésilo}

O autor discorre a respeito da neurose e suas manifestações, sendo que no item "Ritmicidade-Periodicidade", à página 179, ele cita Freud no trecho:

"Há doenças nervosas e mentaes que são essencialmente rítmicas e periódicas. Há neurastenias e dispepsias periódicas. Ciclotimicos são cativos do ritmo, bem como maníaco-depressivos. A irritabilidade emotiva, genital e toxifila obedecem não raro a períodos variantes no mez e no ano. Frequentemente os períodos se acham ligados ao domínio genital, cuja importancia nos débeis nervosos é dominadora. Segundo Freud a histeria, a neurose do medo, são estados que partem de um ponto psico-genital. A doutrina de Freud não é exata em absoluto mas frequentemente o elemento genital material e moral (ciúme, erotismo místico, choque de paixões, perversão, etc.) entram na personalidade do débil nervoso".

\section{7 - 1916 - Anais do Primeiro Congresso Medico Paulista}

- páginas 226-237.

Título do artigo: "Estudo Clinico da Neurastenia"12

\section{Autor: Prof. Henrique Roxo}

O autor iniciou sua palestra de maneira interessante, dizendo que ele pareceria estar buscando uma associação de idéias "por contraste", já que falaria em neurastenia em uma cidade "em que há tanta actividade e progresso". Ele completa esse raciocínio dizendo que nas grandes cidades "sobejam os neurasthenicos", pois a luta pela vida exaure o indivíduo.

Ele procura diferenciar, conforme seus próprios conceitos, neurastenia de nervosismo. Discorrendo sobre o nervosismo, a certa altura ele cita Freud, à pagina 230:

"O nervosismo é mais frequente no sexo feminino e devo chamar a vossa atenção para um facto que a observação clinica tem me permitido constatar. É a frequencia com que o mal se verifica em doentes que praticam relações sexuais incompletas. No afan que se nota geralmente de evitar a procreação, alguns evitam 
ultimar o congresso sexual e a mulher fica nervosa, na ansia de um prazer que se lhe não dá. É uma applicação de Freud que si tem demasias, diz uma grande verdade, quando attribue á sexualidade papel de grande importancia na genesis de psychoses e nevroses".

\section{8 - 1918 - Gazeta Clínica}

- n.12 - dezembro - pg. 196.

Título do artigo: "Psychoscopia"13

\section{Autor: Dr. Henrique Roxo}

O autor utiliza o nome "Psychoscopia" para se referir a uma forma de abordar o paciente procurando observar suas reações a determinados assuntos. Para reforçar sua técnica ele cita a "psycho-analyse":

"Para tal fim o alienista se serve dos recursos que tão úteis foram a Freud e seus discípulos para fazer a psycho-analyse".

Mais adiante ele enfatiza:

"Nada ha mais lindo em sciencia moderna! Lida-se com o alienado como si fora um doente comum, e fazse uma psychotherapia intelligente".

\section{9 - 1919 - Gazeta Clínica}

- ano XVII - n.3 - março - pg. 42-48.

Título do artigo - "Psychasthenia"14

\section{Autor: Dr. Henrique Roxo}

Este artigo vem referido como sendo de novembro de 1916, constando que foi lido e aprovado no Congresso Medico Paulista. O tema e o texto são similares ao artigo dos Anais do Congresso, já referido. No artigo da Gazeta Clínica, à pagina 46, entre comentários a respeito da sexualidade e as alterações psíquicas ele diz que: "É o pleno domínio da doutrina de Freud que na sexualidade busca a origem de todos os males".

\section{0 - 1919 - Gazeta Clínica}

$$
\text { - ano XVII - n.7 - julho - pg. } 137 .
$$

\section{Título da seção - "Bibliographia"15}

\section{Autor: editores.}

Nesta seção intitulada "Bibliographia" a Gazeta Clínica cita as publicações que foram recebidas pela Redação. Nesse mês de julho de 1919, aparece citado o recebimento do livro:

"A doutrina de Freud', pelo Dr. Franco da Rocha, director do Hospicio do Juquery".
Como a publicação do livro de Franco da Rocha "O pansexualismo na doutrina de Freud" ocorreu em 1920, não sabemos se esse registro de 1919, refere-se ao mesmo livro ou algum outro que não tenha chegado a público, e o autor teria mudado de idéia, ou teria feito modificações para a publicação efetiva em 1920.

\section{1 - 1920 - Gazeta Clínica}

- ano XVIII - n.2 - fevereiro - páginas 19-21.

Título do artigo: "Os Mitos e lendas na Loucura" - "cavaco de abertura das aulas de 1920"16

\section{Autor: Dr. Franco da Rocha.}

Neste artigo o autor inicia referindo-se a que a psicopatologia ensina que certas formas de loucura se apresentam como "degenerativas regressões" às fases anteriores do desenvolvimento psíquico da humanidade. Assim, ele refere que, conforme Jung, no "psiconevrotico" ressurgem as formações espirituais que predominavam na humanidade "em fases que, de há muito, se passaram". Mais adiante ele diz que:

"A paleopsicologia, ou estudo dos fósseis da inteligencia humana - das religiões, dos mitos, das fabulas e lendas - bem como o trabalho de etnógrafos, têm prestado grande auxilio ao Prof. Freud e aos seus discípulos - Jung, Otto Rank, Riklin, K. Abraham e outros - na pesquiza das intimas relações que se fazem notar entre a ideação dos nevroticos e psiconevroticos e os processos psíquicos arcaicos do homem das civilizações primitivas".

Após discorrer sobre alguns mitos, o autor volta a citar Freud:

"Na criança a observação dos factos psíquicos é superficial e nos não permite tirar conclusões sobre as forças instintivas que orientam esses factos. Entretanto, há indivíduos adultos que, sob certos pontos de vista, permanecem crianças: são os psiconevroticos. Estes deram ao Prof. Freud ensejo para esses estudos, visto serem suas fantasias reproduções exageradas das fantasias infantis".

"A visão dos psicoanalistas, aguçada pelo continuo exercício da analise psicologica, Ihes permite penetrar na vida da alma humana, até mesmo na alma daqueles que, não sendo nevroticos, mal deixam entrever, em quase apagadas manifestações, as forças instintivas que lhes dirigem a actividade psíquica".

Mais adiante, após o relato do caso de uma paciente, o autor cita:

"Deve-se ao Prof. Freud a analise psicológica de taes factos. É um mérito que the não pode ser negado". 


\section{DISCUSSÃO}

Conforme os dados obtidos, podemos verificar a presença de, pelo menos, onze citações sobre Freud na literatura científica em São Paulo, antes do lançamento formal do livro "O pansexualismo na doutrina de Freud" por Franco da Rocha. Entre as onze citações, duas são do próprio Franco da Rocha, duas são referentes a autores franceses, quatro são de professores do Rio de Janeiro e as duas primeiras de autores paulistas; uma das citações tem duas particularidades especificas: cita o próprio Franco da Rocha e um livro, aparentemente com um nome diferente do mais conhecido e lançado em 1919, um ano antes do suposto inovador livro sobre Freud.

Uma possibilidade de explicação deste último fato é que, talvez esse "texto", ou "livro", entregue à Revista, poderia ser algo como uma "apostila". Em relação a isto, podem-se ler, na introdução do próprio "O pansexualismo na doutrina de Freud", de 1920, as seguintes palavras de Franco da Rocha: "Antes deste livro já havia eu escrito diversas preleções sobre a doutrina de Freud, somente para meus alunos da Faculdade de Medicina de S. Paulo. Pareceu-me, porém, que muitos leitores encontravam dificuldade em compreender toda a doutrina exposta no resumo das preleções, justamente por ser mui conciso"17. Outra possibilidade seria que o autor tivesse desejado modificar o livro para posterior publicação divulgação mais ampla. De qualquer modo, não temos mais dados a respeito desse outro texto de Franco da Rocha; essas são apenas hipóteses para tentar explicar esse "livro antes do livro".

De qualquer modo, pode-se perceber que, provavelmente o nome de Freud, bem como suas idéias, já circulava entre os médicos de São Paulo. As citações observadas podem ser indícios dessa possibilidade. Ao iniciar a introdução de seu livro de 1920, Franco da Rocha já diz que "A publicação deste livro só tem por objectivo transmitir uma noção exacta da doutrina de Freud, que é muito falada e bem pouco conhecida". Essa frase indica, portanto, que já se falava muito em Freud, quando do lançamento do livro.

Além disso, as referências bibliográficas utilizadas pelos autores de artigos médicos em São Paulo, no início do século XX, denotam atualização e contato com informações científicas internacionais que eram recentes em sua própria época. Embora Franco da Rocha tenha se referido, na introdução de sua obra, ao fato de os escritos de Freud serem em alemão, o que teria dificultado seu entendimento em nosso meio, as publicações em francês que citavam Freud acabaram sendo uma via para a chegada de informações a boa parte dos interessados brasileiros; por outro lado, bas- tante conhecedor da língua alemã, Franco da Rocha estudou no original esses escritos. Para ilustrar esse aspecto podemos citar a publicação de artigo de Franco da Rocha em língua alemã, no periódico Zeitschrift für Psychiatrie, no ano de 1899, volume 55, página 133 com o título Bemerkungen über das Vorkommen des Irreseins bei den Negern (Observações sobre o aparecimento da loucura em negros) ${ }^{18}$; também, para reforçar essa ilustração, podemos citar que Franco da Rocha traduzia artigos do alemão para o português, que eram publicados na Revista Médica de São Paulo ${ }^{19}$. Esses são dados que podem corroborar certa acessibilidade de Franco da Rocha aos escritos de Freud.

Um outro fato que podemos observar é que havia um razoável intercâmbio de informações científicas em São Paulo, nessa época (de 1908 a 1920), seja com outros centros nacionais, como o Rio de Janeiro, como com informações de publicações internacionais. Em relação especificamente a Freud, devemos levar em consideração o fato de que uma citação não significa adoção imediata ou mesmo compreensão plena das novas idéias. No entanto, já indica um acesso a informações que eram consideradas recentes, dando uma noção mais dinâmica do conhecimento científico, em São Paulo, nesses anos. Também vemos que, se de um lado havia a possibilidade de acesso a publicações internacionais em tempo ágil, também havia um contato estreito com os cientistas do Rio de Janeiro de maneira singular, na medida em que três dessas publicações citadas foram feitas a partir da presença dos professores A. Austregésilo e Henrique Roxo no Primeiro Congresso Médico Paulista em 1916. Esse Congresso acabou tomando certo caráter de Congresso "nacional", em virtude do comparecimento de delegações de diversos estados, devido ao empenho de seus organizadores, entre eles Franco da Rocha. Aparentemente esse evento parece ter marcado um forte momento para a ciência médica paulista: sua faculdade era de fundação recente, em 1913; houve presença e intercâmbio de vários estados ${ }^{20}$.

A interessante observação de Henrique Roxo, no início de sua fala, sobre a agitação da cidade de São Paulo, uma cidade com "tanta atividade e progresso" parece reforçar esse momento singular da ciência paulistana. Esse parece já ser um ambiente, de certa forma, "preparado" para receber idéias consideradas inovadoras, como as de Freud.

Nesse sentido, um outro aspecto da discussão, é também uma certa noção que se tem de que, apenas a partir de Freud e seus leitores, é que a ciência teria passado a dar atenção às questões sexuais. Para ilustrar esta discussão podemos recorrer a um artigo da primeira publicação médica de São Paulo, de 1889, 
a Revista Medica de São Paulo, que corresponde à tradução de um artigo de Charcot, intitulado "Tratamento da tabes pela suspensão". Esse artigo trata de uma prática terapêutica de "suspensão mecânica" do corpo do paciente, com o intuito de melhorar a sintomatologia decorrente de alterações medulares causadas pela sífilis. Entre esses sintomas havia o comprometimento das funções sexuais. Nesse artigo o prof. Charcot diz que:

"Reconhecemos que a suspensão apresentava como resultado capital a restauração das funcções sexuaes". Sendo assim, compreende-se que Motchokowsky tivesse a idéa de tratar por este meio os impotentes nevropaticos."

"Permitti-nos, senhores, uma digressão. Ha, como sabeis, em Paris e outros paizes, estabellecimentos onde se põem em prática todos os esforços e os meios mais variados para que os impotentes, e sobretudo os velhos recobrem uma virilidade mais ou menos fictícia, capaz pelo menos de assegurar por certo tempo a satisfacção de desejos, mais ou menos naturaes. Pensamos se não seriam conhecidas as virtudes aphrodisicas da suspensão, e, para nos assegurarmos deste facto, enviamos emissários encarregados de colher informações" ${ }^{21}$.

Desse modo, podemos ver que, em 1889, a Medicina e a Ciência já tinham uma atenção voltada para os assuntos e problemas de natureza sexual, aqui nas palavras do próprio Charcot. A publicação desse artigo em periódico médico paulistano indica também uma atenção e uma abertura entre os médicos de São Paulo a essa temática, indicando que não foi apenas a partir de Freud que passou a haver atenção científica à sexualidade em nosso meio.

No que diz respeito a essas noções do "ineditismo de Freud" em relação a diversos assuntos, também sabe-se que ele teve seus antecessores, como por exemplo, na "descoberta" do inconsciente. Durante o século XIX o inconsciente já era um tema entre os intelectuais franceses, bem antes de certa "apropriação" por Freud desse termo em sua doutrina ${ }^{22}$. Além das citações de "inconsciente" e "subconsciente" em alguns desses artigos referidos, podemos observar também, em uma publicação de 1904, na Revista Medica de São Paulo, em artigo intitulado "Gravidez Hysterica" da Dra. Judith Santos, do Rio de Janeiro, o uso do termo "simulação inconsciente" para se referir a uma das explicações para esses casos, citando outros autores que não Freud ${ }^{23}$. (Não é objetivo deste nosso trabalho, mas, em particular, neste artigo científico, há que se notar, nessa época, a publicação desse trabalho de autoria de uma médica em um ambiente então dominado pelo sexo masculino).
No sentido de trocas de informações e influências, o contato estreito dos intelectuais e cientistas brasileiros com a França, pode ter facilitado o ambiente a estar aberto a discussões em torno do inconsciente e temas semelhantes, que já vinham sendo ligados a noções em torno do psiquismo e do sistema nervoso.

Pelos diferentes fatores citados, a partir da noção de "mito de origem" ou "mito de fundação", pode ser notado, de maneira similar ao que ocorre em outros campos científicos - guardadas as devidas proporções - que a publicação de Franco da Rocha, "O pansexualismo da doutrina de Freud", de 1920, passou a ser considerado como um marco na história dos estudos da psicologia, da psicanálise e da psiquiatria.

Por outro lado, uma procura mais detalhada de dados anteriores a esse ano, pode mostrar que a transição entre o antes e o depois dessa data não se deu de forma abrupta, mas sim gradual, com a presença de Freud pelo menos a partir de doze anos antes desse ano, em São Paulo. A época a partir de 1920 pode delimitar um período cujos contextos, social, cultural e artístico, já estavam propícios a certa "oficialidade" das idéias freudianas na ciência e arte paulistanas.

\section{CONCLUSÕES}

A partir dessas discussões podemos considerar que no início do século XX, na cidade de São Paulo, houve uma gradual penetração das idéias de Freud, bem antes do que era suposto (1920), pelo menos a partir de 1908.

Uma análise desses elementos, a partir da conceituação de "mito de fundação" ou "mito de origem", pode fazer supor que a publicação de Franco da Rocha, "O pansexualismo da doutrina de Freud", em 1920, acabou se tornando um marco fundamental, ou mesmo fundador dos estudos e práticas relacionados à psicanálise em São Paulo, que acabou reforçando o papel do Movimento Modernista em relação à aceitação e divulgação da psicanálise em São Paulo e no Brasil, já que esse movimento eclodiu a partir da Semana de Arte Moderna de 1922. A importância desses fatos já tem sido citada em outras publicações. Em nosso caso, estamos acentuando a questão do "mito de origem" envolvendo essa publicação.

A partir de uma visão embasada na idéia de "paradigma científico" pode-se observar que, durante as primeiras décadas do século XX, ao mesmo tempo em que a cidade de São Paulo era "veloz" na progressão de sua complexidade, a ciência paulista pode ter tido cada vez mais dificuldades em responder às indagações científicas de natureza psíquica com os paradigmas então vigentes, de modo que, já a partir 
de 1908, há indícios de busca de respostas a essas indagações através de outros paradigmas, como, neste caso, com elementos da doutrina freudiana. A constatação de Henrique Roxo, em 1916, ao dar a sua palestra, sobre neurastenia, em um ambiente que lhe parecia propício ao seu tema, reforçou essa nossa hipótese de transição de paradigmas destinados ao entendimento de fatores psíquicos, nessa época, em São Paulo.
Pelos dados obtidos pode-se constatar que não houve períodos "estanques", como sendo, de um lado, a década de 1910 com Freud conhecido entre os médicos do Rio de Janeiro, e, por outro lado, na década de 1920 entre os artistas em São Paulo. Houve, na verdade, uma interligação, uma troca de informações entre médicos do Rio de Janeiro, de São Paulo, e de outros locais, de modo que os diferentes grupos compartilhavam informações a respeito da doutrina freudiana.

\section{REFERÊNCIAS BIBLIOGRÁFICAS}

1. Oliveira CLMV. História da Psicanálise - São Paulo (1920-1969). São Paulo: Editora Escuta, Fapesp, 2006, p. 35-36-37.

2. Russo J. O Mundo Psi no Brasil.Rio de Janeiro: Jorge Zahar Editor, 2002 , p. 17.

3. Vandermeersch P. Les Mythes d'origine. In: Micale MS, Porter R (eds). The history of psychiatry in discovering the history of psychiatry. Oxford: Oxford University Press, 1994, p. 219-231.

4. Neves AC. Humanização da Medicina e seus mitos. São Paulo: Editora Companhia llimitada, 2005, p. 38-48.

5. Kuhn TS. A estrutura das revoluções científicas. São Paulo: Editora Perspectiva, 2003, 264p.

6. Gonçalves J. Ideas fixas e obsessões. Gazeta Clinica, ano VII, 1909; 4:44-46.

7. Villas-Boas A. A physio-pathologia da vontade. Gazeta Clínica, ano VIII, 1910, 7: 73-75.

8. Rocha F. Paranoia e syndrome paranoide. Annaes Paulistas de Medicina e Cirurgia, ano II, 1914; 2(3): 65-75.

9. Dumas G. Os milagres de Esculapio. Gazeta Clínica, ano XII, 1914; 2: 45-46.

10. Hesnard A. As theorias psychologicas e metapsychologicas da demencia precoce. Gazeta Clínica, ano XII, 1914; 9: 194.

11. Austregésilo A. Debilidade nervosa - reações elementares do Sistema Nervoso. Annaes do Primeiro Congresso Medico Paulista, 1916, p. 176-185.
12. Roxo H. Estudo clinico da neurastenia". Annaes do Primeiro Congresso Medico Paulista, 1916, p. 226-237.

13. Roxo H. Psychoscopia. Gazeta Clinica, ano XVI, 1918; 2:196.

14. Gazeta Clínica - seção "Bibliographia", ano XVII, 1919; 7:137.

15. Roxo H. Psychastenia. Gazeta Clínica, ano XVIII, 1920; 2:19-21.

16. Rocha F. Os mitos e lendas na loucura - cavaco de abertura das aulas de 1920. Gazeta Clinica, ano XVIII, 1920; 2:19-21.

17. Rocha F. O pansexualismo na doutrina de Freud. São Paulo: Typographia Brasil de Rothschild \& Cia., 1920

18. Seção "Revista das Revistas" - Revista Medica de São Paulo, 1899, p. 223.

19. Sodré A, Couto M. Epidemiologia da Febre Amarella. Tradução Rocha F. Enciclopédia Médica Alemã de Nothnagel (Specielle Pathologie und Therapie herausgegeben von Hofrath Prof. H. Nothnagel, V. Band, IV Theil, II Abteilung. Das Gelbefieber) . Revista Medica de São Paulo, 1903, p. 173.

20. Annaes do Primeiro Congresso Medico Paulista - Actas da Comissão Organizadora. A Sessão Preparatória, 1916, p. 13-30.

21. Charcot JM. Tratamento da tabes pela suspensão. Revista Medica de São Paulo, 1889, p. 23-27.

22. Cazeto SJ. A constituição do inconsciente em práticas clinicas na França do século XIX. São Paulo: Editora Escuta, Fapesp, 2001.

23. Santos J. Gravidez Hysterica. Revista Medica de São Paulo, ano VII, 1904, p. 379-384. 